Check for updates

Cite this: RSC Adv., 2019, 9, 18547

\title{
Kinetically-controlled laser-synthesis of colloidal high-entropy alloy nanoparticles $\uparrow$
}

\author{
Friedrich Waag, ${ }^{a}$ Yao Li, ${ }^{a}$ Anna Rosa Ziefuß, ${ }^{a}$ Erwan Bertin, $\ddagger^{\mathrm{a}}$ Marius Kamp, ${ }^{\mathrm{b}}$ \\ Viola Duppel, ${ }^{c}$ Galina Marzun, ${ }^{a}$ Lorenz Kienle, ${ }^{b}$ Stephan Barcikowski (D) ${ }^{a}$ \\ and Bilal Gökce (iD *a
}

\begin{abstract}
The single-step incorporation of multiple immiscible elements into colloidal high-entropy alloy (HEA) nanoparticles has manifold technological potential, but it continues to be a challenge for state-of-theart synthesis methods. Hence, the development of a synthesis approach by which the chemical composition and phase of colloidal HEA nanoparticles can be controlled could lead to a new pool of nanoalloys with unparalleled functionalities. Herein, this study reports the single-step synthesis of colloidal CoCrFeMnNi HEA nanoparticles with targeted equimolar stoichiometry and diameters less than $5 \mathrm{~nm}$ by liquid-phase, ultrashort-pulsed laser ablation of the consolidated and heat-treated micropowders of the five constituent metals. Further, the scalability of the process with an unprecedented productivity of 3 grams of colloidal HEA nanoparticles per hour is demonstrated. Electrochemical analysis reveals a unique redox behavior of the particles' surfaces in an alkaline environment and a potential for future application as a heterogeneous catalyst for the oxygen evolution reaction.
\end{abstract}

Received 1st May 2019

Accepted 29th May 2019

DOI: $10.1039 /$ c9ra03254a

rsc.li/rsc-advances

\section{Introduction}

High-entropy alloys (HEAs) have evolved to one of the most popular material classes in the last decades in both fundamental and applied material science. ${ }^{1-3}$ Unique mechanical, ${ }^{4-6}$ electromagnetic, ${ }^{7-9}$ and electrochemical ${ }^{\mathbf{1 0 - 1 2}}$ properties originate from their multi-elemental, solid-solution character. However, research has been focused primarily on bulk HEA, ignoring HEA nanoparticles (NPs), due to the absence of a reliable, scalable, and straightforward synthesis method for HEA NPs. Very recently, HEA NPs with up to eight elements, i.e., Pt, Pd, Co, Ni, $\mathrm{Fe}, \mathrm{Cu}, \mathrm{Au}$, and $\mathrm{Sn}$, were produced by the carbothermal shock synthesis. ${ }^{13}$ The remarkable method allows uniform elemental distributions in single NPs that thereafter are kinetically controllable in size by the shock duration with a minimum diameter of $3 \mathrm{~nm}$. However, carbothermal shock synthesis only produces NPs immobilized on conductive, surface-oxidized carbon support materials, and that limits the possibilities for

${ }^{a}$ Technical Chemistry I, Center for Nanointegration Duisburg-Essen (CENIDE), University of Duisburg-Essen, 45141 Essen, Germany.E-mail: bilal.goekce@uni-due.de ${ }^{b}$ Synthesis and Real Structure, Institute for Materials Science, Kiel University, 24143 Kiel, Germany

${ }^{c}$ Nanochemistry, Max Planck Institute for Solid State Research, 70569 Stuttgart, Germany

$\dagger$ Electronic supplementary information (ESI) available. See DOI: 10.1039/c9ra03254a

+ Present address: Department of Chemistry, University of Calgary, Calgary, $A B$, T2N 1N4, Canada. industrial application. In another recent approach, CoCrCuFeNi-HEA NPs with $9 \mathrm{~nm}$ diameter immobilized on graphene were synthesized by mechanical ball milling of single metal powders mixed with graphene. ${ }^{14}$ This solid-state synthesis is more convenient than the carbothermal shock synthesis but cannot achieve the targeted chemical distribution of the NPs. A production route for CoCrCuNiAl-HEA NPs with an average diameter of $14 \mathrm{~nm}$ is based on the popular sol-gel autocombustion process. ${ }^{15}$ However, no colloidal NPs have been produced by the method so far, and the chemical compositions of the NPs that were synthesized were not studied in detail. By plasma arc discharge synthesis, CoCrCuFeNi-HEA NPs of average diameters larger than $80 \mathrm{~nm}$ were produced in a reactive gas atmosphere. ${ }^{16}$ This method is advantageous in terms of simplicity and scalability but is bound to the gas phase and yields only large HEA NPs.

In brief, none of the above-mentioned studies describes the synthesis of colloidal HEA NPs. There are only two known synthesis approaches for isolated, colloidal HEA NPs. The first approach was published in 2015. ${ }^{17}$ A common wet chemical approach was used and the obtained NPs had large diameters (26.7 $\mathrm{nm}$ ) with strong deviations in the chemical composition from the targeted equimolar CoCrCuFeNi. The second approach yielded in ultrasmall CoCrFeMnNi NPs with diameters ranging from 2 to $4 \mathrm{~nm}$ with either amorphous or crystalline structure depending on the experimental parameters. ${ }^{18}$ By sputtering material from a nearly equimolar HEA target into an ionic liquid, NPs can be synthesized instead of films usually 
obtained by the method. However, the required ionic liquid and the complexity of the method strongly limit its applicability. Accordingly, since the first observation of spherical nanoprecipitations in bulk HEA, ${ }^{19}$ no successful, scalable synthesis of colloidal HEA NPs with targeted elemental composition has been reported.

In this work, we demonstrate the simple, reproducible, and scalable synthesis of isolated, colloidal NPs of the equimolar CoCrFeNiMn HEA, first investigated by Cantor et al., ${ }^{20}$ by picosecond-pulsed laser ablation of a solid CoCrFeNiMn HEA target immersed in a flow cell. Since the first report on laser synthesis of colloids was published, ${ }^{21}$ the method ultimately became a competitive method for the synthesis of NP colloids. ${ }^{22-25}$ With this synthesis approach, we were able to obtain highly stable colloids of isolated HEA NPs without the use of any ligands for stabilization. To demonstrate the industrial applicability, we also investigated the reproducibility and scalability of the laser-based method. The investigation of the reproducibility of the approach included the evaluation of the performance of the as-synthesized NPs of the CoCrFeNiMn HEA loaded on carbon black (CB) for the oxygen evolution reaction (OER) in alkaline environment.

\section{Results and discussion}

\section{Colloidal state of the laser ablation product}

Picosecond-pulsed laser ablation of CoCrFeMnNi HEA targets in ethanol yielded brownish-colored, transparent liquids, indicating the formation of a NP colloid. Fig. 1 shows a qualitative representation of the general formation mechanism of NPs during picosecond-pulsed laser ablation of bulk targets immersed in liquids. ${ }^{26}$ In the zoom into the atomic scale, we considered the likely ablation process and NP formation for the laser ablation of a HEA ablation target. In brief, a laser beam of sufficient energy fluence irradiates the surface of a bulk HEA (Fig. 1a), leading to the formation of a plume. Later a cavitation bubble is formed (Fig. 1b) by the ablation of hot atoms, ions and clusters from the bulk HEA and their mixing with the liquid's vapor (Fig. 1b, left zoom). Then, the plume cools and the ablated species condense (Fig. 1b, right zoom). Ultimately, the growth of the condensates is quenched and they are released as NPs to the liquid during the collapse of the cavitation bubble (Fig. 1c). The HEA ablation targets were produced by mixing, pressing, and heat-treating of micropowders of the single metals. Fig. S1 (ESI $\dagger$ ) shows a simplified sketch of the different steps in the entire procedure, starting at single metal micropowders and resulting in NPs.

Analytic disc centrifugation (ADC) analysis of the liquids synthesized by laser-ablation of HEA targets revealed the presence of NPs with a bimodal volume-weighted size distribution with peak maxima at hydrodynamic diameters of 7.7 and $87.7 \mathrm{~nm}$ (Fig. 2a). It remained unclear from the ADC measurement, if particles larger $300 \mathrm{~nm}$ existed in the colloid. By transmission electron microscopy, no particles with Feret diameters larger than $100 \mathrm{~nm}$ were found (Fig. S2 and S13, ESI $\dagger$ ). Furthermore, a size fraction smaller than the limit for reliable detection of NPs with moderate gravimetrical density by ADC showed up during TEM analysis. Analytical ultracentrifugation (AUC) was applied at different rotation speeds for a statistically reliable determination of the size distribution at small diameters.

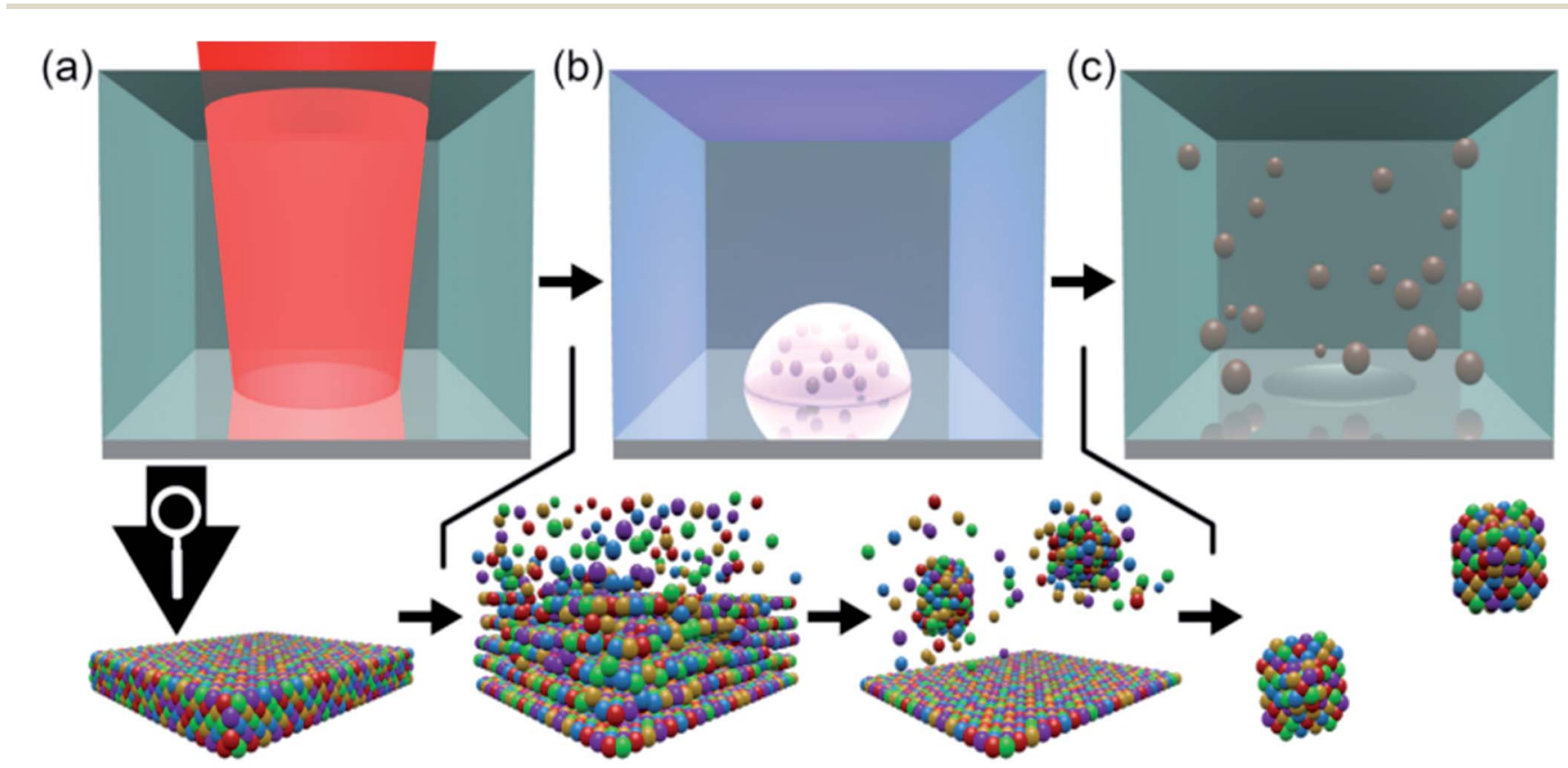

Fig. 1 Qualitative representation of the laser-based synthesis of high-entropy alloy nanoparticles. The synthesis method consisted of the following stages: ultrashort-pulsed laser irradiation of the bulk high-entropy alloy (HEA) (a), the atomization/ionization of the bulk causing the formation of a plume, and subsequent nucleation and condensation of the ablated matter in the vapor phase of the liquid (b) and the colloidal high-entropy alloy nanoparticles electrostatically stabilized in ethanol (c). 

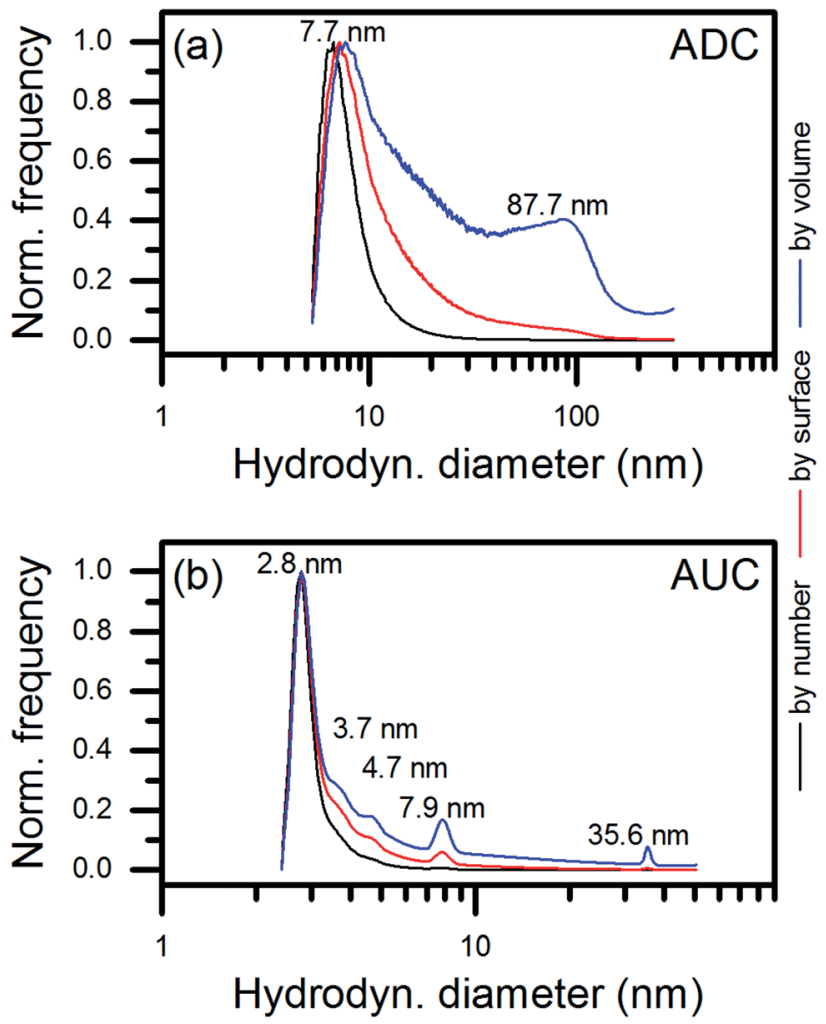

Fig. 2 Relative number, surface and volume frequencies vs. hydrodynamic diameter measured by analytical disc centrifugation (a) and analytical ultracentrifugation (b). The positions of the maxima of the different fractions found in the volume-related size distributions were marked in the diagrams.

In contrast to ADC, AUC enables the analysis of colloidal particles down to the sub-nanometer scale. ${ }^{27}$ Therefore, we used this third technique of size measurement to determine whether the ultrasmall NPs observed in the TEM micrographs were present as non-agglomerated NPs in the colloid. Fig. 2b shows that most of the synthesized NPs had hydrodynamic diameters of $2.8 \mathrm{~nm}$. Therefore, AUC confirmed the existence of isolated, ultrasmall NPs in the colloid. Interestingly, a second dominant size mode with an average hydrodynamic diameter of $7.9 \mathrm{~nm}$ was observed in the AUC measurement data. This mode is in good agreement with the main size mode detected in the ADC measurement at $7.7 \mathrm{~nm}$ (Fig. 2a) and the TEM analysis. An indication of a third dominant size mode at $35.6 \mathrm{~nm}$ appeared in the volume-related size distribution measured by AUC. This value was in good agreement with the onset of the second size mode in the ADC data. However, the size mode contributed differently to the results of both methods for unclear reasons. Conclusively, NPs of diameters smaller than $5 \mathrm{~nm}$ made the main product of the laser ablation of HEA targets in ethanol by number, surface, and volume. Minor amounts of particles of 5 to $10 \mathrm{~nm}$ and 30 to $100 \mathrm{~nm}$ contributed only to the surface- and the surface- and volume-related size distributions measured by AUC.

The presence of different size fractions in the colloids that were produced can be assigned to distinct particle formation mechanisms in the picosecond-pulsed laser synthesis of colloids. ${ }^{28}$ Whereas ultrasmall NPs originate from nucleation and condensation in a low-density mixing region of the ablated metal species and the liquid environment in a supercritical state, larger NPs emerge from a highly dynamic molten layer on the surface of the ablation target due to Rayleigh-Taylor instability. However, the main product of the picosecond-pulsed laser ablation consisted of ultrasmall NPs, predicted to be formed in the low-density region. ${ }^{26}$ The small hydrodynamic diameters of laser-generated NPs result from fast kinetics. Cooling rates of the condensates in the order of $10^{12} \mathrm{~K} \mathrm{~s}^{-1}$ can be expected, ${ }^{26}$ and passivation of the surface of the NPs that occurs by the interaction with solvent species suppresses further growth. ${ }^{29,79}$

\section{Crystal structure of the laser-generated nanoparticles}

Next, we investigated the crystal structure of NPs by X-ray diffraction (XRD), selected area electron diffraction (SAED), and high-resolution transmission electron microscopy (HRTEM). Generally, the single metals of CoCrFeMnNi crystallize in different structures, which was demonstrated by the diffractogram of the micropowder mixture (Fig. S3a and d, ESI $\dagger$ ). The diffractograms of the ablation target and a dried colloid shown in Fig. 3 consisted mainly of three reflections, which could be assigned to the (111), (200), and (220) planes of a single fcc lattice. The $d$-values are presented in Table 1 . They slightly diverged by about $+0.01 \AA$ from the plane distances for bulk equimolar CoCrFeMnNi reported in the literature, ${ }^{30-33}$ which was probably in the range of the uncertainty of the method. The results confirmed the HEA nature of the ablation target and the preservation or reformation of the HEA structure in the total volume of NPs during the laser-based synthesis.

Additional peaks showed up in the diffractogram of the dried colloid, and this was in good agreement with a spinel-type structure. The extracted lattice parameter of $8.44 \AA$ was comparable to that of magnetite, which has been reported as

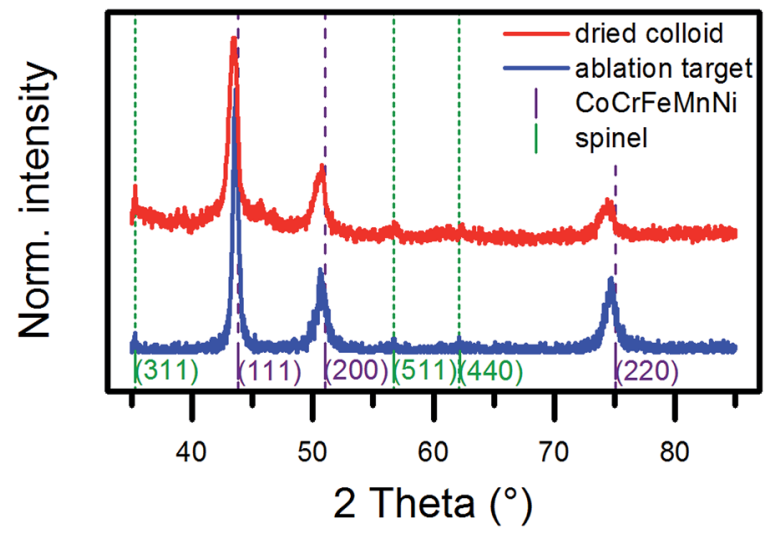

Fig. 3 X-ray diffractograms of the ablation target (blue line) and a dried colloid produced in ethanol (red line). The violet lines mark the reflections expected for a CoCrFeMnNi HEA with a lattice parameter of $3.58 \AA .{ }^{30}$ The green lines mark the expected reflections for a spineltype oxide with a lattice parameter of $8.44 \AA$, which is close to that of manganese chromite. ${ }^{35}$ 
Table 1 Extracted $d$-spacing values of lattice analysis. $d$-spacing values extracted from $\mathrm{X}$-ray diffractograms of the ablation target and a dried colloid produced in ethanol (Fig. 3), extracted from electron diffraction data of a nanoparticle agglomerate (Fig. 4a) and calculated values based on a lattice parameter of $3.58 \AA^{30}$

\begin{tabular}{lllll}
\hline Plane & Calculation & Target, XRD & $\begin{array}{l}\text { Particles, } \\
\text { XRD }\end{array}$ & $\begin{array}{l}\text { Particles, } \\
\text { SAED }\end{array}$ \\
\hline$(111)$ & $2.08 \AA$ & $2.08 \AA$ & $2.08 \AA$ & $2.08 \AA$ \\
$(200)$ & $1.79 \AA$ & $1.80 \AA$ & $1.81 \AA$ & $1.81 \AA$ \\
$(220)$ & $1.27 \AA$ & $1.27 \AA$ & $1.28 \AA$ & $1.28 \AA$ \\
\hline
\end{tabular}

$8.39 \AA{ }^{34}$ but it fitted best with manganese chromite. ${ }^{35}$ The reflection of the (311) plane also appeared in the diffractogram of the ablation target. A reliable determination of the phase composition by a Rietveld analysis of the diffraction data of the dried colloid proved difficult because of the presence of singlecrystalline NPs of different sizes in the ablation product. However, the low peak intensities of the oxide phase indicated only a minor share. The broadening in the base of the peak of the (111) reflection of the fcc lattice of the dried colloid most likely originated from a superposition of the diffractions of crystallites of different sizes. In conclusion, XRD analysis proved the HEA nature of the laser-generated NPs and strongly indicated the HEA nature of the ultrasmall NPs due to their dominant volume contribution (Fig. 2).

To verify the XRD results at the nanoscale, we applied selected area electron diffraction (SAED) at hundreds of NPs deposited on a $\mathrm{Cu}$ grid (Fig. $4 \mathrm{a}$ and b). Obviously, the NPs were crystalline, and, again, the diffraction pattern fitted the fcc lattice. Comparable lattice parameters to those determined by XRD resulted from SAED (Table 1). This finding was validated by investigations of single NPs from different size fractions. The single and larger crystalline NPs ( $c f$. bright-field image in Fig. 4c) can be assigned to the fcc crystal structure, as indicated by the respective electron diffraction pattern (Fig. $4 \mathrm{~d}$, zone axis [101]). In addition, the fast Fourier transform (Fig. 4f) calculated from the HRTEM micrograph of a single and smaller NP (Fig. 4e) shows a corresponding [101] zone axis pattern. The periodic nature of the average structure also is supported by the HRTEM micrograph of Fig. 4g. These findings indicate the same crystal structure for NPs from the small size fraction and give clear evidence of the HEA nature of the NPs produced by pulsed laser ablation of the CoCrFeMnNi HEA target in ethanol. However, there is a fraction of large ( $>50 \mathrm{~nm}$ ) NPs in the sample showing an incident of a defect structure in accordance with the XRD results (Fig. 3). The lamellar defects (Fig. $4 \mathrm{~h}$ ) of some larger NPs represented by diffuse [111 $]^{*}$ streaks and reflection splitting in SAED (Fig. 4i) could be assigned to the formation of $\Sigma 3$ twin due to relaxation similar to bulk observations. ${ }^{36}$ SAED revealed a reduction of spacing of the (111) lattice, which coincided with the asymmetric shape of the (200) reflection in the XRD diffractogram towards smaller 2 theta angles (Fig. 3). Further characterization of the defect structure by HRTEM is provided in the ESI (Fig. S4). $\dagger$ Interestingly, the larger NPs, which showed a $\Sigma 3$-twin formation, also exhibited surface
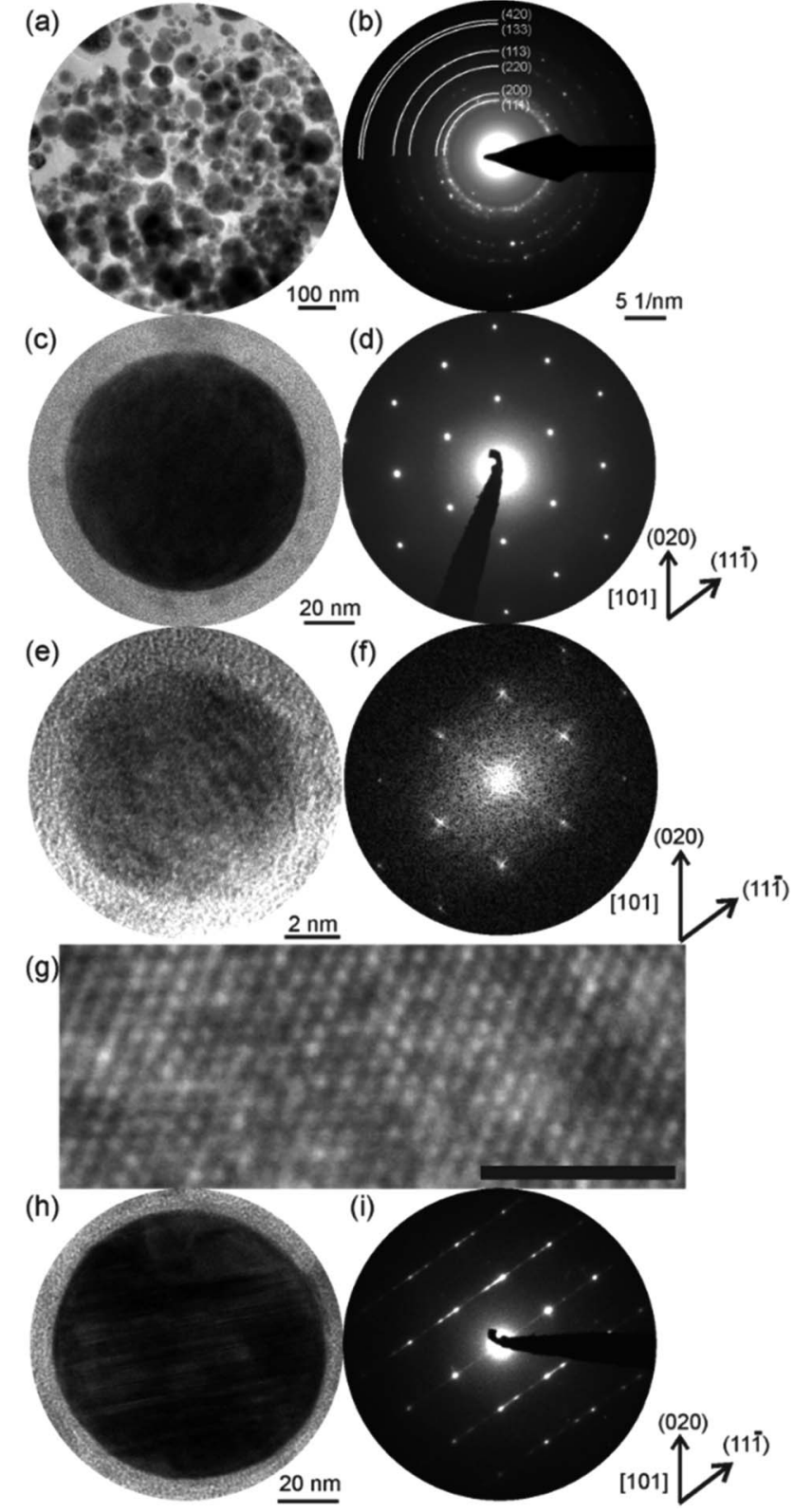

Fig. 4 Bright-field image of multiple CoCrFeMnNi HEA NPs (a) and the respective diffraction pattern (b) proving the fcc-type structure of the NPs. In (c) a single and larger crystalline nanoparticle is shown with the respective diffraction pattern in (d). The same crystal structure is determined for small nanoparticles by the high-resolution TEM micrograph (e) and the respective fast Fourier transform ( $f$ ). An inset of (e) is magnified in (g) (scale bar is $1 \mathrm{~nm}$ ). High-resolution TEM micrograph of a large disordered NP (>100 nm) (h) and the respective diffraction pattern with diffuse streaks and reflection splitting (i).

segregation of $\mathrm{Cr}$ and $\mathrm{Mn}$ (Fig. S5, ESI $\dagger$ ). The surface segregation also corresponded to our observation by XRD of the Cr-, Mn-based spinel oxide phase (Fig. 3).

The size selectivity of the surface segregation of $\mathrm{Cr}$ and $\mathrm{Mn}$, which probably occurred along with the oxidation in the spinel structure, indicated an origin in the formation of the NPs. This finding agreed with the results of the atomistic model on the 
formation of NPs in the ultrashort-pulsed laser ablation of metals in liquids. ${ }^{26,28}$ The results of the model predict different residence times of larger NPs released from the molten surface layer into the hot, low-density mixing region of the ablated metal species and the supercritical solvent according to their kinetic energies. The movements of the laser-ablated species away from the ablation target at different velocities was also shown experimentally for the femtosecond-pulsed laser ablation of aluminum in vacuum. ${ }^{37} \mathrm{~A}$ longer residence time in the low-density mixing region probably caused an intensified interaction with oxygen, which formed during the splitting of the solvent. ${ }^{38}$ Subsequently, the surface segregation of $\mathrm{Cr}$ and Mn took place by selective oxidation in our experiments. Both metals naturally exhibit a higher oxidation potential than $\mathrm{Co}, \mathrm{Fe}$ and Ni. Other larger NPs with higher kinetic energies left the low-density mixing region during their formation and cooled down faster without undergoing surface segregation. Consequently, we can conclude that surface segregation and oxidation were part of a late stage of the particle formation and only affected a small amount of larger NPs. Due to the lower heat capacity of smaller NPs their cooling may have taken place faster without surface segregation.

\section{Chemical composition of laser-generated HEA nanoparticles}

Initially, we investigated the chemical composition of the ablation target before and after the synthesis of HEA NPs by scanning electron microscopy (SEM) and energy dispersive X-ray (EDX) analysis. Fig. 5a shows a SEM image of the ablation target, depicting the border of the laser ablation area on the surface of the target. The rough surface of the target in the ablation zone on the left side of the image is clearly visible. Fig. $5 \mathrm{~b}$ shows the exemplary EDX mapping of a $120 \times 120 \mu \mathrm{m}$-sized area of the ablation target for all five elements. We found a homogeneous distribution of each element. The ESI $\dagger$ also includes an EDX mapping of an ablation area (Fig. S6, ESI $\dagger$ ). Table 2 provides the atomic fractions of the five single elements in the ablation area and on the nonablated surface of the target. Each value represents the average of a mapping area of the size shown in Fig. 5b. The deviation of the elemental composition of the target, evaluated from three measurements at different positions on the surface of the target as
Table 2 Molar fractions of $\mathrm{Co}, \mathrm{Cr}, \mathrm{Fe}, \mathrm{Mn}$, and $\mathrm{Ni}$ measured in the ablated and non-ablated area of the surface of the ablation target by energy dispersive $\mathrm{X}$-ray spectroscopy and the maximum deviation evaluated from three measurements at different positions of the surface of the target. Each measurement was performed as a mapping of a $120 \times 120 \mu \mathrm{m}$ area and averaged afterwards. The average molar fractions of the single metals determined for HEA NPs are shown in comparison

\begin{tabular}{llllll}
\hline & Co & Cr & Fe & Mn & Ni \\
\hline Ablation & 0.198 & 0.219 & 0.197 & 0.192 & 0.194 \\
Non-ablation & 0.209 & 0.196 & 0.197 & 0.201 & 0.197 \\
Max. deviation & 0.004 & 0.009 & 0.008 & 0.011 & 0.018 \\
NPs & 0.206 & 0.178 & 0.217 & 0.182 & 0.218 \\
Std. deviation & 0.018 & 0.009 & 0.005 & 0.001 & 0.006
\end{tabular}

a maximal deviation from the median, also is shown in Table 2. More SEM images and EDX results on the micropowders and ablation targets are provided in the ESI (Fig. S7-S12). $\dagger$ The variations in the composition of the ablated and non-ablated surface area fitted the maximum deviation between several measurements. We conclude that no selective ablation of single elements from the target took place, which ensured that equal molar amounts of each of the elements became part of the colloid.

Investigation of the elemental distribution within a single NP took place by EDX mapping. Fig. $5 \mathrm{c}$ demonstrates a homogeneous distribution of the five elements within a single NP. Despite some technical challenges and low counts on single NPs, the quantitative composition in Table 2 depicts the average of multiple NPs. The agglomerate of HEA NPs had a nearly equimolar composition.

A homogeneous chemical composition of single ultrasmall NPs only can be assumed based on the analysis of the crystal structure that was presented, because the EDX scanning area cannot be restricted to such small areas. In case of strong deviations from the chemical composition of the ablation target, a significant change in the phase composition, or at least the lattice parameter, should have occurred in the NPs. This was observed neither by SAED (Fig. 4) nor by XRD (Fig. 3) as summarized in Table 1, even though the ultrasmall NPs dominated the product by volume (Fig. 2). In addition, significant deviations from the equimolar composition only were observed within single larger NPs.
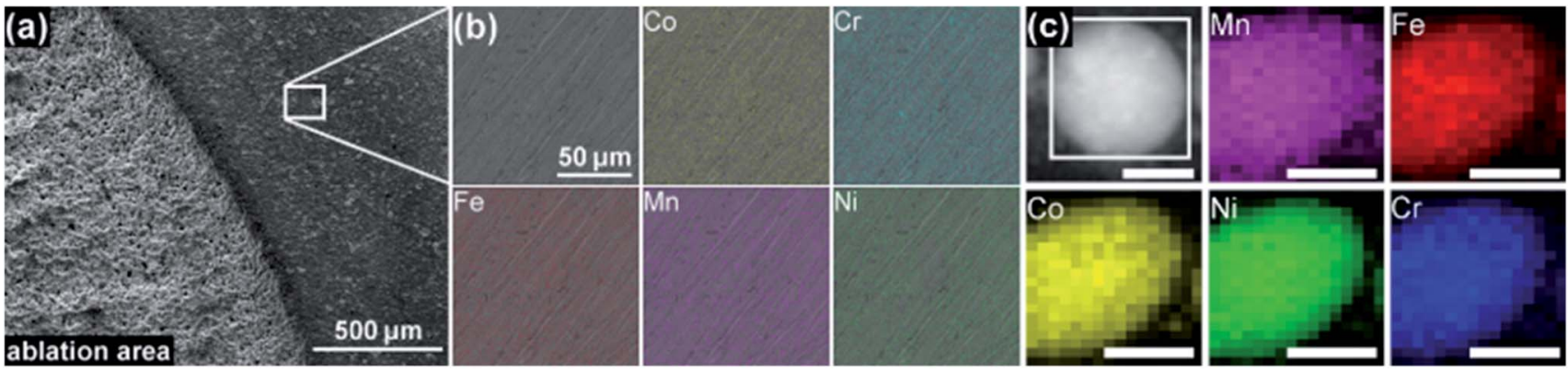

Fig. 5 Scanning electron microscope image (secondary electrons) of an ablation target near the border of an ablation area (a), elemental maps of $\mathrm{Co}, \mathrm{Cr}, \mathrm{Fe}, \mathrm{Mn}$, and $\mathrm{Ni}$ obtained by energy dispersive $\mathrm{X}$-ray spectroscopy of a non-ablated target area (b), and scanning transmission electron microscopy image and elemental maps of $\mathrm{Co}, \mathrm{Cr}, \mathrm{Fe}, \mathrm{Mn}$, and $\mathrm{Ni}$ for a single nanoparticle (c). In (a), the laser ablation area is located on the left side of the image. In (c), all scale bars represent $25 \mathrm{~nm}$. 
Investigation of the relevance of the synthesis approach for industrial application in terms of scalability, reproducibility, and demand

In order to emphasize the relevance of the synthesis approach to the application of the laser-based synthesis of HEA NP colloids, we modified the synthesis process for use with a highpower laser system. (See also the description in the Experimental section.) As an initial step in modification, we replaced ethanol as the ablation liquid with water. This mainly was due to the higher rates of ablation using water instead of ethanol..$^{38,39}$ In addition, water is both economically and ecologically advantageous compared to ethanol.

The XRD data of the NPs synthesized in different solvents indicated slight differences in the crystal structure (Fig. 6a). The HEA-related diffraction peaks of the NPs produced in water showed a shift in the reflection angle. In addition, relatively higher intensities of diffractions related to the before mentioned spinel oxide phase, especially for the (400) plane, occurred. However, it remained unclear from the results whether the amount of phase-segregated, larger NPs increased or smaller NPs underwent phase segregation during the lasersynthesis in water. The further adaption of the water-based synthesis to the high-power laser system, adapted from Streubel et al., ${ }^{40}$ yielded a mass ablation rate of $3 \mathrm{~g} \mathrm{~h}^{-1}$, which was 50 times higher than the mass ablation rate using ethanol in the setup at the low-power laser system. As demonstrated by the XRD data, similar amounts of oxide showed up for NPs synthesized in water at both low and high laser power. A comparison of the size distribution of the NPs produced in ethanol at the low-power laser and those produced in the scaleup by TEM (Fig. S2, ESI $\dagger$ ) exhibited a slight shift of the ultrasmall size fraction of the NPs to larger diameters for the scaledup NP colloids. This change probably originated from the larger extent of the oxidation of the surface of the NPs synthesized in water, which was also indicated by low-contrast shells around the particles in the TEM micrographs (Fig. S13, ESI $\dagger$ ).

We investigated further the effect of the upscaling process on the performance of the NPs in a chosen application. Lasergenerated NP colloids exhibit a high potential for various applications. ${ }^{24}$ The NPs can be immobilized easily on conductive $^{41-48}$ and non-conductive ${ }^{49-54}$ substrates and be used, for instance, in additive manufacturing, ${ }^{48,51}$ as sensors, ${ }^{41,54}$ or in energy conversion and storage. ${ }^{\mathbf{4 3 , 4 5}}$ For colloids based on polar solvents, an optimization of the deposition process can be achieved by adjusting the static charge on the surfaces of the NPs and the substrate, ${ }^{52}$ or by applying an electric field between the substrate and a counter electrode. ${ }^{\mathbf{4 4 , 4 9}}$ The ligand-free surfaces of the laser-generated NPs enable their effective adsorption on substrates. ${ }^{50,55}$ In addition, the surface charges of the laser-generated NPs cause their unique electrostatic stabilization properties. $^{56}$ The absence of stabilizing ligands promotes, in particular, the application of laser-generated NPs in heterogeneous catalysis. $^{57}$ Consequently, we prepared heterogeneous catalysts by immobilization of the lasergenerated HEA NPs on CB (Fig. S14, ESI $\dagger$ ). Due to the relevance of alloys and mixed oxides of the transition metals of Co,
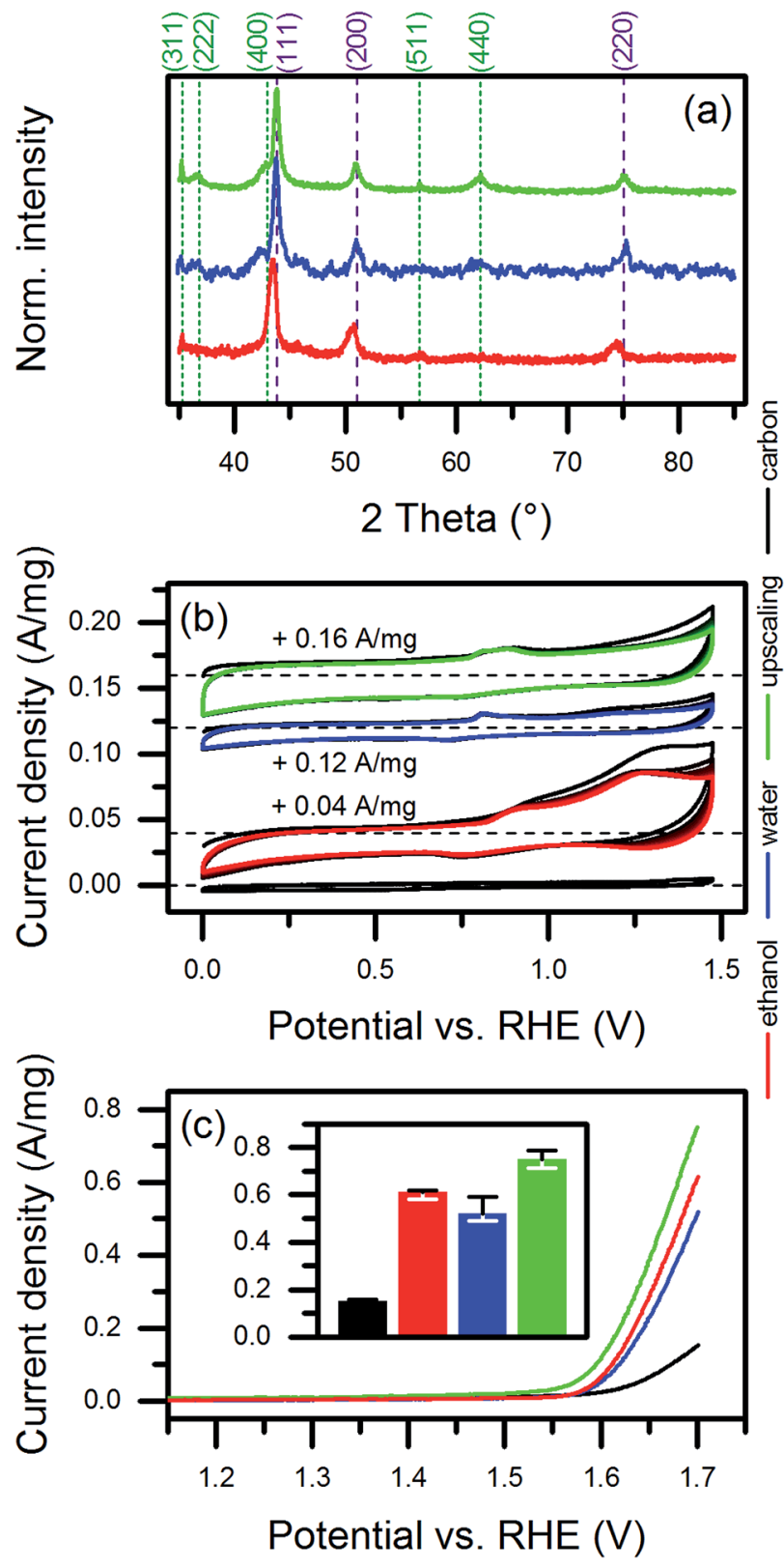

Fig. 6 X-ray diffraction analysis of dried colloids from the laser ablation in ethanol, in water, and from the upscaling approach (a), and electrochemical characterization of the nanoparticles immobilized on carbon black by cyclic (b) and linear sweep (c) voltammetry. The lattice planes marked in (a) correspond to diffractions expected for $\mathrm{CoCr}$ FeMnNi with a lattice parameter of $3.58 \AA$ (violet lines) and to diffractions expected for a spinel-type oxide with a lattice parameter of $8.44 \AA$ (green lines). The inset in (c) shows the current densities extracted at $1.7 \mathrm{~V}$ vs. RHE. The error bars in (c) represent the maximum deviation evaluated from three measurements.

$\mathrm{Fe}, \mathrm{Mn}$ and Ni for electrochemical water splitting, ${ }^{\mathbf{5 8 - 6 0}}$ we tested the potential of the HEA for alkaline OER.

As shown in Fig. 6b, the catalysts produced from NPs synthesized in ethanol, water, and the upscaling approach responded differently in cyclic voltammetry, suggesting a change in the composition of the surface (discussed further below). The initial decrease in anodic currents observed for all 
catalysts probably originated from the removal of impurities during cycling. A significantly higher decrease in the currents measured for the ethanol-based catalyst most likely was linked to organic leftovers from ethanol or laser-decomposition products of ethanol. Interestingly, the dominance and positions of the characteristic redox features varied slightly for the different catalysts and only two to three redox features appeared for each catalyst. The presence of five metals in the NPs complicated the assignment of contributions to the observed currents. For instance, a $\mathrm{NiOOH} / \mathrm{Ni}(\mathrm{OH})_{2}$ transition, which likely occurs at a voltage higher than $1.25 \mathrm{~V} v s$. RHE at $\mathrm{pH} 13$, can shift to an even higher voltage in case of alloying Ni with Fe. ${ }^{61}$ Alloying Ni with Co causes the opposite effect. ${ }^{62}$ Li et al. ${ }^{63}$ described effects of exchanging the alloy partner in Co-based, binary NPs by Fe, $\mathrm{Mn}$, and Ni on the redox behavior of the particles. Considering the observed surface segregation of $\mathrm{Cr}$, the $\mathrm{Cr}(\mathrm{III}) / \mathrm{Cr}(\mathrm{VI})$ transition is another candidate that would fit at least the oxidation feature at higher voltages. ${ }^{64}$ Due to the solubility of $\operatorname{Cr}(\mathrm{vI})$, probably no reduction peak would be assignable. However, in that case, the oxidation peak also should decrease during cycling, which we did not observe. Mn accompanied $\mathrm{Cr}$ in the surface segregation. Some redox transitions of $\mathrm{Mn}$, i.e., $\mathrm{Mn}_{3} \mathrm{O}_{4}$ / $\mathrm{MnOOH}$ and $\mathrm{MnOOH} / \mathrm{MnO}_{2}$, could have lied in the cycled potential range.$^{65}$ Due to the close positions of the oxidization and reduction waves of the $\mathrm{Mn}$ reaction, the two expected peaks for the oxidation and the reduction reactions, respectively, may have overlapped in the voltammogram. Moreover, we were unable to detect any features close to the expected voltages for Fe-related reactions. ${ }^{64,66}$

In conclusion, unique electrochemical properties of the surfaces of the catalysts appeared. Synergetic effects caused by the presence of different metals contributed to the redox features. In addition, the solvent that was used during the synthesis and the used laser influenced the potentials of the redox reactions. Further analysis of the particle surfaces, such as X-ray photoelectron spectroscopy, should shed light on the elemental compositions of the surfaces in future studies.

We extracted the current densities at $1.7 \mathrm{~V} v s$. RHE from the linear sweep voltammograms to investigate the suitability for OER catalysis (Fig. 6c). The currents were related to the mass of NPs $(1.96 \mu \mathrm{g})$ used to produce the amount of catalyst deposited on the glassy carbon electrode for each electrochemical measurement. In case of pure CB, the same mass was used. Interestingly, no significant difference showed up for NPs synthesized in ethanol or water. However, the NPs produced in the upscaling approach performed best, which was probably caused by the slightly different redox behavior of their surfaces. A comparison of the achieved mass activities to literature data (Fig. 7a) revealed a good performance of our catalysts. We considered only studies, which conducted the electrochemical characterization similar to ours. $\mathrm{Basu}^{67}$ synthesized $\mathrm{Co}_{3} \mathrm{O}_{4}$ catalysts immobilized on differently prepared, carbon-based supports and achieved a maximum mass activity of $0.077 \mathrm{~A}$ $\mathrm{mg}^{-1}$ at $1.7 \mathrm{~V} v$ s. RHE. The value was significantly lower than the $0.104 \mathrm{~A} \mathrm{mg}^{-1}$ reached in average for the water-based HEA NPs on CB. However, the author used a lower scan rate of $5 \mathrm{mV} \mathrm{s}^{-1}$ and a stronger electrolyte $(1 \mathrm{M} \mathrm{NaOH})$ compared to our study
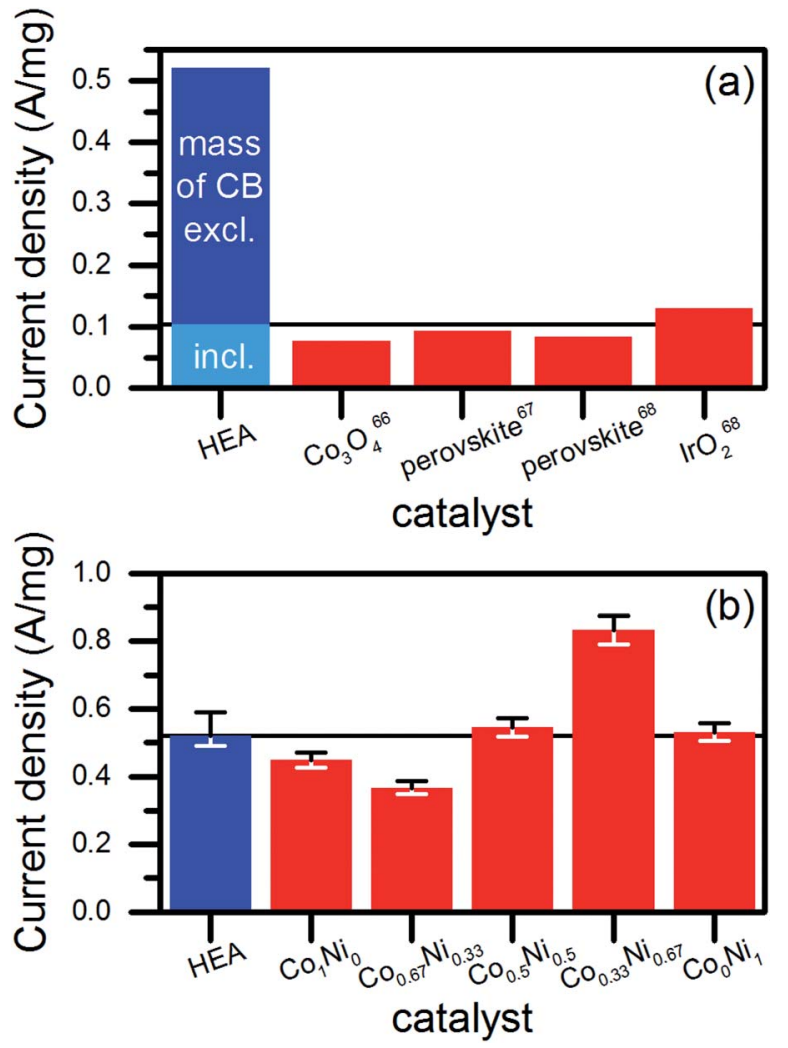

Fig. 7 Comparison of the mass-related current density or mass effectivity of HEA NPs (water-based synthesis at low-power laser) to literature data (a) and to catalysts based on NPs from the laser ablation of $\mathrm{Co}_{x} \mathrm{Ni}_{x-1}$ targets, which were produced the exact same way as the HEA NPs. The black line in both diagrams marks the mass activity of the HEA catalyst for alkaline OER. The error bars in (b) represent the maximum deviation evaluated from three measurements in case of the HEA sample and the systematic error of the electrochemical measurement of $5 \%$ in case of the other samples.

(20 $\left.\mathrm{mV} \mathrm{s}^{-1}, 0.1 \mathrm{M} \mathrm{NaOH}\right)$. In two studies on multi-element perovskite catalysts, ${ }^{\mathbf{6 8 , 6 9}}$ the authors determined maximal mass activities of 0.093 (ref. 68) and $0.085 \mathrm{~A} \mathrm{mg}^{-1}$ (ref. 69) at a potential close to $1.7 \mathrm{~V} v s$. RHE. Interestingly, Xu et $a .^{69}$ measured also the activity of a commercial $\mathrm{IrO}_{2}$ catalyst as 0.13 $\mathrm{A} \mathrm{mg}^{-1}$, which was $25 \%$ higher than the HEA NP synthesized in water at the low-power laser but $13 \%$ lower compared to those synthesized at the high-power system.

However, such comparisons always lack comparability due to differences in the preparation of the electrodes and the measurement procedure. Therefore, we synthesized NPs by the laser ablation of binary alloy targets of $\mathrm{Co}$ and $\mathrm{Ni}$ in water (Fig. S15, ESI $\dagger$ ). Mixed materials of Co and Ni represent efficient OER catalysts. ${ }^{70,71}$ The production of the ablation targets, the NP synthesis and the electrochemical characterization took place at identical parameters compared to the HEA. As shown in Fig. 7b, the HEA NPs achieved similar mass activities than the $\mathrm{Co}_{x} \mathrm{Ni}_{1-x}$ NPs. Exceptions appeared for the Co-rich and Ni-rich compositions, which showed significantly lower (30\%) and higher $(60 \%)$ mass activities related to the activity of the HEA NPs, 
respectively. This dependency of the catalytic performance on the ratio of Co to Ni agreed with the literature. ${ }^{72,73}$

For the investigation of the reproducibility of the NP synthesis, we varied different process parameters within the ablation of CoCrFeMnNi HEA targets in ethanol using the lowpower laser system and within the target and catalyst preparation. We monitored the effect on the light extinction properties of the colloids (Fig. S16-S20, ESI $\dagger$ ) and their catalytic performance represented by the current density at $1.7 \mathrm{~V} v s$. RHE (Fig. S21 and S22, ESI $\dagger$ ). From the wavelength-dependent extinction of light, we extracted information on the productivity $^{74}$ and the size distribution ${ }^{75}$ of the NP colloid. The parameters that were varied included the duration of the heattreatment of the ablation targets (Fig. S18, ESI $\dagger$ ), the distance between the focal plane and the target surface during the synthesis (Fig. S19, ESI $\dagger$ ), and the repeated use of a single ablation target for the synthesis of NP colloids (Fig. S20, ESI †). We observed that the laser synthesis of NP colloids from ablation targets of the CoCrFeMnNi HEA was highly reproducible (with variations of less than 10\%) in terms of the productivity and size distribution.

In using the catalytic performance of the NPs as the figure of merit for the synthesis process, the highest deviation of $12 \%$ was observed for catalysts produced from three different targets heat-treated for $20 \mathrm{~h}$ (Fig. S21b, ESI $\dagger$ ) and from three targets heat-treated for different durations (Fig. S21c, ESI $\dagger$ ). We conclude that the preparation of the ablation targets, and most likely the mixing step of the metal micropowders, introduced the highest deviation in the electrochemical performance of the catalysts. However, the deviation was still in the range of acceptance for industrial application.

The demonstrated procedure for the laser-based synthesis of HEA NPs proved scalability and reproducibility. Moreover, a brief outlook on an application of the NPs as heterogeneous catalysts for OER indicated an existing potential. However, NPs produced by the laser ablation of binary alloys of $\mathrm{Co}$ and $\mathrm{Ni}$ revealed comparable and in one case even higher mass activities. Consequently, we will focus on variations of the composition of the CoCrFeMnNi alloy to identify the most active one in future studies. In addition, the quantitative and structural analysis with relation to the NP surface needs to be extended to investigate the origin of the catalytic performance.

\section{Experimental}

\section{Pulsed laser ablation in liquid}

Laser-based synthesis of HEA NPs was performed by using a 10 ps pulsed Nd:YAG laser (Atlantic, Ekspla, Vilnius, Lithuania) at a wavelength of $1064 \mathrm{~nm}$, a repetition rate of $100 \mathrm{kHz}$, and a power of $8.8 \mathrm{~W}$ behind all optics. We used a thermopile sensor (PowerMax PM30, Coherent, Santa Clara, USA) to measure the power of the laser. After leaving the laser source, the laser beam with a raw beam diameter of about $2 \mathrm{~mm}$ (manufacturer's specification) enters a galvanometer scanner (SCANcube 10, SCANLAB, Puchheim, Germany) and afterwards passes through an $\mathrm{f}$-theta lens with a focal length of $100 \mathrm{~mm}$ that focuses the beam on an HEA sheet mounted in a flow chamber. A constant volumetric flow of $20 \mathrm{~mL} \mathrm{~min}{ }^{-1}$ was applied to the ablation fluid, i.e., ethanol (99.8\%, Thermo Fisher Scientific, Waltham, USA) streaming through the ablation chamber.

A demonstration of the scalability of the synthesis method was performed using a 3 ps pulsed high-power laser system (500 flex, AMPHOS, Herzogenrath, Germany) in steady-state conditions of a liquid flow of $500 \mathrm{~mL} \mathrm{~min}{ }^{-1} .^{40}$ The wavelength of the laser was $1030 \mathrm{~nm}$ and the pulse repetition rate was $10 \mathrm{MHz}$. Spatial separation of single laser pulses on the ablation target was achieved by applying a scanning speed of $484 \mathrm{~m} \mathrm{~s}^{-1}$. The optimal working distance for the ablation was adjusted by determining the maximized ablation rate via UV-vis extinction measurements (Evolution 201, Thermo Fisher Scientific, Waltham, USA) of colloids produced at different working distances. The ablation at the high-power laser system was performed in water (Milli-Q, Merck, Darmstadt, Germany).

\section{Preparation of the ablation targets}

Ablation targets of the CoCrFeNiMn HEA were produced by weighting, homogenizing, pressing, and heat-treating (in an argon atmosphere) of micropowders of the single metals. All powders were purchased from Alfa Aesar (Haverhill, USA). Purities and grain sizes are as follows (supplier specifications): Co $(99.8 \%, 1.6 \mu \mathrm{m}), \mathrm{Cr}(99.2 \%,<10 \mu \mathrm{m}), \mathrm{Fe}(99.5 \%,<10 \mu \mathrm{m}), \mathrm{Mn}$ $(99.6 \%,<10 \mu \mathrm{m})$, Ni $(99.9 \%, 3-7 \mu \mathrm{m})$. To achieve an equimolar composition, the powders were weighed in the mass ratio $1: 0.88: 0.95: 0.93: 1$, following the preceding order. The powders were homogenized by a pestle in a mortar for $20 \mathrm{~min}$ before pressing the powder mixture at $200 \mathrm{MPa}$ to sheets of $20 \times$ $20 \times 2 \mathrm{~mm}$. The sheets were heat-treated in an argon atmosphere for $20 \mathrm{~h}$ at $1000^{\circ} \mathrm{C}$ to trigger the formation of the fcc HEA atomic lattice by diffusion. A thin oxide layer on the heat-treated sheets, which likely was caused by oxygen from the oxidized surfaces of metal micrograins, was removed by sanding. The ablation targets were mechanically processed to fit in the ablation chamber.

\section{Preparation and electrochemical characterization of the catalysts}

To prepare heterogeneous catalysts from the laser-generated NPs, colloids were mixed with a dispersion of carbon black (VULCAN XC72R, Cabot Corporation, Boston, USA) in equal volumes. $\mathrm{CB}$ was dispersed in the same liquid that was used for the laser synthesis of the NP colloids. To achieve a specific mass loading of NPs on carbon black, the mass loss of the ablation target during the synthesis of the NPs was determined, and CB was weighed accordingly. Mixing of the dispersions occurred $1 \mathrm{~h}$ after the synthesis of the colloids of the NPs. The mixture of the two dispersions was stored for $20 \mathrm{~min}$ in an ultrasonic bath. Afterward, the liquid was evaporated to obtain a dry catalyst powder.

The electrochemical investigation of the catalysts was performed by utilizing a three-electrode setup at a potentiostat (VersaSTAT F3, Princeton Applied Research, Ametek, Berwyn, USA). All measurements were performed in $0.1 \mathrm{M} \mathrm{NaOH} \mathrm{(pH}=$ 13) by using a Pt counter electrode and an $\mathrm{Ag} / \mathrm{AgCl}$ reference 
electrode. All potentials were corrected with respect to reversible hydrogen electrode (RHE). Inks of the HEA/CB catalyst were prepared by dispersing HEA/CB (4.9 mg) in a $1: 1$ (by volume) mixture $(5 \mathrm{~mL})$ of Milli-Q water and isopropyl alcohol (99.6\%, Thermo Fisher Scientific, Waltham, USA) with $5 \mathrm{wt} \%$-Nafion ionomer solution ( $40 \mu \mathrm{L}, 15-20 \%$ water, Sigma Aldrich, St. Louis, USA) with subsequent sonication. Then, a volume $(10 \mu \mathrm{L})$ of a catalyst ink was drop casted on a glassy carbon electrode and dried for $15 \mathrm{~min}$ by rotating at $700 \mathrm{rpm}$. Before each measurement, the electrolyte was degassed for $30 \mathrm{~min}$ with argon. Blank cyclic voltammetry was performed at a sweep of $100 \mathrm{mV} \mathrm{s}^{-1}$ (without any rotation of the electrode). All linear sweep measurements were conducted at a sweep of $20 \mathrm{mV} \mathrm{s}^{-1}$, and current densities were extracted at $1.7 \mathrm{~V}$ (electrode rotation of $1600 \mathrm{rpm}$ ) for sample comparison. All currents were related to the mass of NPs $(1.96 \mu \mathrm{g})$ deposited on the glassy carbon electrode $\left(0.196 \mathrm{~cm}^{2}\right)$.

\section{Analytical ultracentrifugation (AUC)}

A precise, high-resolution analysis of the size distribution of the NPs was conducted by AUC of the colloids based on ethanol. The ultracentrifuge (ProteomeLab XL-I, Beckmann Coulter, Brea, USA) was used at speeds of 5000; 15000 and $20000 \mathrm{rpm}$ for the colloid analysis. The different speeds allowed a detailed investigation of the hydrodynamic diameters of the NPs in the range of 1 to $50 \mathrm{~nm}$. The used rotor type was an AN-60 Ti with $12 \mathrm{~mm}$ path length and a radius of $65 \mathrm{~mm}$. Sedimentation velocities were detected in 200 scans at $20^{\circ} \mathrm{C}$. The absorbance was detected at $400 \mathrm{~nm}$.

\section{Analytical disc centrifugation (ADC)}

ADC measurement was used for a statistically reliable determination of the sizes of the HEA NPs produced in ethanol and water using the low-power laser system. Measurements were performed using a disc centrifuge (DC 24000, CPS instruments, Prairieville, USA) using the maximum speed of $24000 \mathrm{rpm}$ and a water-based sucrose gradient. The ethanol-based samples were mixed with water in the ratio of $1: 5$ to ensure a proper measurement.

\section{Scanning electron microscopy (SEM) and energy dispersive X- ray spectroscopy (EDX)}

A scanning electron microscope (XL 30, Philips, Amsterdam, Netherlands) equipped with a $\mathrm{Si}(\mathrm{Li})$-EDX-detector was used for the investigation of the uniformity of the chemical composition of the ablation targets.

\section{X-ray diffraction analysis (XRD)}

XRD analysis was performed on the rasped ablation targets and the dried colloids using a diffractometer (Empyrean, PANalytical, Almelo, Netherlands) with Bragg-Brentano geometry and $\mathrm{Cu} \mathrm{K} \alpha$ radiation.

\section{Transmission electron microscopy (TEM)}

Analyses were performed of the morphologies and sizes of the HEA NPs produced by the low- and high-power laser system and the catalysts using a transmission electron microscope (CM12 Philips, Amsterdam, Netherlands). All samples were drop casted on a carbon-coated $\mathrm{Cu}$ mesh. High-resolution transmission electron microscopy (HRTEM) and EDX investigations were performed with a Tecnai F30 STwin G2 $300 \mathrm{kV}$ acceleration voltage and a $\mathrm{Si}(\mathrm{Li})$ detector (EDAX system for elemental maps). Scanning TEM Z-contrast images were recorded using a highangle, annular, dark-field detector, and a Philips CM30 ST microscope (LaB6 cathode, $300 \mathrm{kV}$ ) was used for the HRTEM and selected area electron diffraction (SAED) studies.

\section{UV-vis extinction spectroscopy}

The spectroscopic analysis was performed on colloids filled in a quartz glass cuvette (10 $\mathrm{mm}$ beam way). Each extinction spectrum was recorded at an extinction-calibrated spectrometer (Evolution 201, Thermo Fisher Scientific, Waltham, USA) in the range of 190 to $1100 \mathrm{~nm}$ versus a background spectrum of pure ethanol.

\section{Conclusions}

In summary, the ultrafast laser synthesis of colloids proved feasible to synthesize colloidal NPs of CoCrFeMnNi HEA with a targeted chemical composition. An fcc lattice fitting the equimolar CoCrFeMnNi HEA was determined by XRD, SAED, and in HRTEM imaging for NPs of different diameters. In addition, on average, a nearly equimolar elemental composition was determined for the HEA NPs. Furthermore, we verified the colloidal state of ultrasmall $(<5 \mathrm{~nm})$ HEA NPs by using centrifugal size measurement techniques. The isolated, colloidal nature of our HEA NPs in the absence of stabilizers enabled the immobilization of laser-synthesized NPs on different substrates. An exemplary application in heterogeneous catalysis of the alkaline OER by immobilization of the HEA NPs on CB was performed successfully in this study. The remarkable stability of the laser-synthesis approach was verified based on the low deviations in the catalytic performance of the HEA NPs that were produced. Further, we provided evidence of the industrial applicability by scaling up of the synthesis process and producing a yield of $3 \mathrm{~g} \mathrm{~h}^{-1}$. The catalytic performance of the synthesized HEA NPs is promising, but a comparison to laser-generated CoNi NPs reveals the potential for further optimization by variation of the alloy composition.

Prospectively, the capability for rapid production of different functional materials by the variation of the alloy composition of the ablation target, ${ }^{76}$ by the combination of the target material and the liquid environment, ${ }^{77}$ and by exchanging the immobilization substrate, as discussed earlier, make the laser-based synthesis superior for screening nanomaterials. In particular, varying the amount of single elements in multinary, non-noble metal alloy NPs holds the chance of finding a specific composition, which may, for instance, in future challenge platinum as 
fuel cell catalyst. ${ }^{78}$ The laser-based synthesis may cover both the material screening and technical scale production.

\section{Conflicts of interest}

There are no conflicts to declare.

\section{Acknowledgements}

The authors gratefully acknowledge the German Federal Ministry of Education and Research (03SF0497B) and the German Research Foundation (GO 2566/2-1, BA 3580/18-1 and KI 1263/15-1) for funding. E. B. gratefully acknowledges the support of the Alexander von Humboldt Foundation for a postdoctoral fellowship.

\section{Notes and references}

1 M. H. Tsai and J. W. Yeh, High-entropy alloys: a critical review, Mater. Res. Lett., 2014, 2, 107.

2 Y. Zhang, T. T. Zuo, Z. Tang, M. C. Gao, K. A. Dahmen, P. K. Liaw and Z. P. Lu, Microstructures and properties of high-entropy alloys, Prog. Mater. Sci., 2014, 61, 1.

3 D. B. Miracle and O. N. Senkov, A critical review of high entropy alloys and related concepts, Acta Mater., 2017, 122, 448.

4 O. N. Senkov, G. B. Wilks, D. B. Miracle, C. P. Chuang and P. K. Liaw, Refractory high-entropy alloys, Intermetallics, 2010, 18, 1758.

5 Z. Li, K. G. Pradeep, Y. Deng, D. Raabe and C. C. Tasan, Metastable high-entropy dual-phase alloys overcome the strength-ductility trade-off, Nature, 2016, 534, 227.

6 J. Moon, M. J. Jang, J. W. Bae, D. Yim, J. M. Park, J. Lee and H. S. Kim, Mechanical behavior and solid solution strengthening model for face-centered cubic single crystalline and polycrystalline high-entropy alloys, Intermetallics, 2018, 98, 89.

7 Y. Zhang, T. Zuo, Y. Cheng and P. K. Liaw, High-entropy alloys with high saturation magnetization, electrical resistivity, and malleability, Sci. Rep., 2013, 3, 1455.

8 P. Koželj, S. Vrtnik, A. Jelen, S. Jazbec, Z. Jagličić, S. Maiti, M. Feuerbacher, W. Steurer and J. Dolinšek, Discovery of a superconducting high-entropy alloy, Phys. Rev. Lett., 2014, 113, 107001.

9 P. Li, A. Wang and C. T. Liu, A ductile high entropy alloy with attractive magnetic properties, J. Alloys Compd., 2017, 694, 55.

10 X. Cui, B. Zhang, C. Zeng and S. Guo, Electrocatalytic activity of high-entropy alloys toward oxygen evolution reaction, MRS Commun., 2018, 8, 1230.

11 H. Luo, Z. Li, A. M. Mingers and D. Raabe, Corrosion behavior of an equiatomic CoCrFeMnNi high-entropy alloy compared with 304 stainless steel in sulfuric acid solution, Corros. Sci., 2018, 134, 131.

12 G. Zhang, K. Ming, J. Kang, Q. Huang, Z. Zhang, X. Zheng and $\mathrm{X}$. Bi, High entropy alloy as a highly active and stable electrocatalyst for hydrogen evolution reaction, Electrochim. Acta, 2018, 279, 19.

13 Y. Yao, Z. Huang, P. Xie, S. D. Lacey, R. J. Jacob, H. Xie, F. Chen, A. Nie, T. Pu, M. Rehwoldt, D. Yu, M. R. Zachariah, C. Wang, R. Shahbazian-Yassar, J. Li and L. Hu, Carbothermal shock synthesis of high-entropy-alloy nanoparticles, Science, 2018, 359, 1489.

14 M. Y. Rekha, N. Mallik and C. Srivastava, First report on high entropy alloy nanoparticle decorated graphene, Sci. Rep., 2018, 8, 8737.

15 B. Niu, F. Zhang, H. Ping, N. Li, J. Zhou, L. Lei, J. Xie, J. Zhang, W. Wang and Z. Fu, Sol-gel autocombustion synthesis of nanocrystalline high-entropy alloys, Sci. Rep., 2017, 7, 3421.

16 A. Mao, H. Xiang, X. Ran, Y. Li, X. Jin, H. Yu and X. Gu, Plasma arc discharge synthesis of multicomponent Co-CrCu-Fe-Ni nanoparticles, J. Alloys Compd., 2019, 775, 1177.

17 M. P. Singh and C. Srivastava, Synthesis and electron microscopy of high entropy alloy nanoparticles, Mater. Lett., 2015, 160, 419.

18 A. Garzón-Manjón, H. Meyer, D. Grochla, T. Löffler, W. Schuhmann, A. Ludwig and C. Scheu, Controlling the amorphous and crystalline state of multinary alloy nanoparticles in an ionic liquid, Nanomaterials, 2018, 8, 903.

19 J.-W. Yeh, S.-K. Chen, S.-J. Lin, J.-Y. Gan, T.-S. Chin, T.-T. Shun, C.-H. Tsau and S.-Y. Chang, Nanostructured high-entropy alloys with multiple principal elements: novel alloy design concepts and outcomes, Adv. Eng. Mater., 2004, 6, 299.

20 B. Cantor, I. T. H. Chang, P. Knight and A. J. B. Vincent, Microstructural development in equiatomic multicomponent alloys, Mater. Sci. Eng., 2004, 375, 213.

21 A. Fojtik and A. Henglein, Laser ablation of films and suspended particles in a solvent: formation of cluster and colloid solutions, Ber. Bunsenges. Phys. Chem., 1993, 97, 252.

22 Z. Yan and D. B. Chrisey, Pulsed laser ablation in liquid for micro-/nanostructure generation, J. Photochem. Photobiol., C, 2012, 13, 204.

23 H. Zeng, X.-W. Du, S. C. Singh, S. A. Kulinich, S. Yang, J. He and W. Cai, Nanomaterials via laser ablation/irradiation in liquid: a review, Adv. Funct. Mater., 2012, 22, 1333.

24 D. Zhang, B. Gökce and S. Barcikowski, Laser synthesis and processing of colloids: fundamentals and applications, Chem. Rev., 2017, 117, 3990.

25 D. Zhang, J. Liu, P. Li, Z. Tian and C. Liang, Recent Advances in Surfactant-Free, Surface-Charged, and Defect-Rich Catalysts Developed by Laser Ablation and Processing in Liquids, ChemNanoMat, 2017, 3, 512.

26 C. Y. Shih, C. Wu, M. V. Shugaev and L. V. Zhigilei, Atomistic modeling of nanoparticle generation in short pulse laser ablation of thin metal films in water, J. Colloid Interface Sci., 2017, 489, 3.

27 K. L. Planken and H. Cölfen, Analytical ultracentrifugation of colloids, Nanoscale, 2010, 2, 1849.

28 C.-Y. Shih, R. Streubel, J. Heberle, A. Letzel, M. V. Shugaev, C. Wu, M. Schmidt, B. Gökce, S. Barcikowski and L. V. Zhigilei, Two mechanisms of nanoparticle generation 
in picosecond laser ablation in liquids: the origin of the bimodal size distribution, Nanoscale, 2018, 10, 6900.

$29 \mathrm{~V}$. Amendola and M. Meneghetti, What controls the composition and the structure of nanomaterials generated by laser ablation in liquid solution?, Phys. Chem. Chem. Phys., 2013, 15, 3027.

30 A. J. Zaddach, C. Niu, C. C. Koch and D. L. Irving, Mechanical properties and stacking fault energies of NiFeCrCoMn highentropy alloy, J. Met., 2013, 65, 1780.

31 J. Y. He, W. H. Liu, H. Wang, Y. Wu, X. J. Liu, T. G. Nieh and Z. P. Lu, Effects of $\mathrm{Al}$ addition on structural evolution and tensile properties of the FeCoNiCrMn high-entropy alloy system, Acta Mater., 2014, 62, 105.

32 F. Otto, A. Dlouhý, C. Somsen, H. Bei, G. Eggeler and E. P. George, The influences of temperature and microstructure on the tensile properties of a CoCrFeMnNi high-entropy alloy, Acta Mater., 2013, 61, 5743.

33 P. P. Bhattacharjee, G. D. Sathiaraj, M. Zaid, J. R. Gatti, C. Lee, C.-W. Tsai and J.-W. Yeh, Microstructure and texture evolution during annealing of equiatomic CoCrFeMnNi high-entropy alloy, J. Alloys Compd., 2014, 587, 544.

34 M. E. Fleet, The structure of magnetite, Acta Crystallogr., Sect. B: Struct. Crystallogr. Cryst. Chem., 1981, 37, 917.

35 J. M. Hastings and L. M. Corliss, Magnetic structure of manganese chromite, Phys. Rev., 1962, 126, 556.

36 G. Laplanche, A. Kostka, O. M. Horst, G. Eggeler and E. P. George, Microstructure evolution and critical stress for twinning in the CrMnFeCoNi high-entropy alloy, Acta Mater., 2016, 118, 152.

37 S. Amoruso, R. Bruzzese, M. Vitiello, N. N. Nedialkov and P. A. Atanasov, Experimental and theoretical investigations of femtosecond laser ablation of aluminum in vacuum, $J$. Appl. Phys., 2005, 98, 044907.

38 M.-R. Kalus, N. Bärsch, R. Streubel, E. Gökce, S. Barcikowski and B. Gökce, How persistent microbubbles shield nanoparticle productivity in laser synthesis of colloidsquantification of their volume, dwell dynamics, and gas composition, Phys. Chem. Chem. Phys., 2017, 19, 7112.

39 A. Kanitz, J. S. Hoppius, M. Fiebrandt, P. Awakowicz, C. Esen, A. Ostendorf and E. L. Gurevich, Impact of liquid environment on femtosecond laser ablation, Appl. Phys. A, 2017, 123, 674.

40 R. Streubel, S. Barcikowski and B. Gökce, Continuous multigram nanoparticle synthesis by high-power, highrepetition-rate ultrafast laser ablation in liquids, Opt. Lett., 2016, 41, 1486.

41 X. Xu, G. Duan, Y. Li, G. Liu, J. Wang, H. Zhang, Z. Dai and W. Cai, Fabrication of gold nanoparticles by laser ablation in liquid and their application for simultaneous electrochemical detection of $\mathrm{Cd}^{2+}, \mathrm{Pb}^{2+}, \mathrm{Cu}^{2+}, \mathrm{Hg}^{2+}, A C S$ Appl. Mater. Interfaces, 2013, 6, 65.

42 V. L. Kumar, R. S. S. Siddhardha, A. Kaniyoor, R. Podila, M. Molli, S. M. Kumar, K. Venkataramaniah, S. Ramaprabhu, A. M. Rao and S. S. Ramamurthy, Gold decorated graphene by laser ablation for efficient electrocatalytic oxidation of methanol and ethanol, Electroanalysis, 2014, 26, 1850.

43 S. Wu, P. Wang, Y. Cai, D. Liang, Y. Ye, Z. Tian, J. Liu and C. Liang, Reduced graphene oxide anchored magnetic $\mathrm{ZnFe}_{2} \mathrm{O}_{4}$ nanoparticles with enhanced visible-light photocatalytic activity, RSC Adv., 2015, 5, 9069.

44 S. Koenen, R. Streubel, J. Jakobi, K. Schwabe, J. K. Krauss and S. Barcikowski, Continuous electrophoretic deposition and electrophoretic mobility of ligand-free, metal nanoparticles in liquid flow, J. Electrochem. Soc., 2015, 162, D174.

45 D. Liang, Z. Tian, J. Liu, Y. Ye, S. Wu, Y. Cai and C. Liang, $\mathrm{MoS}_{2}$ nanosheets decorated with ultrafine $\mathrm{Co}_{3} \mathrm{O}_{4}$ nanoparticles for high-performance electrochemical capacitors, Electrochim. Acta, 2015, 182, 376.

46 P. Pradhan, R. Podila, M. Molli, A. Kaniyoor, V. S. Muthukumar, S. S. S. Sai, S. Ramaprabhu and A. M. Rao, Optical limiting and nonlinear optical properties of gold-decorated graphene nanocomposites, Opt. Mater., 2015, 39, 182.

47 R. Torres-Mendieta, D. Ventura-Espinosa, S. Sabater, J. Lancis, G. Mínguez-Vega and J. A. Mata, In situ decoration of graphene sheets with gold nanoparticles synthetized by pulsed laser ablation in liquids, Sci. Rep., 2016, 6, 30478.

48 C. Doñate-Buendía, F. Frömel, M. B. Wilms, R. Streubel, J. Tenkamp, T. Hupfeld, M. Nachev, E. Gökce, A. Weisheit, S. Barcikowski, F. Walther, J. H. Schleifenbaum and B. Gökce, Oxide dispersion-strengthened alloys generated by laser metal deposition of laser-generated nanoparticlemetal powder composites, Mater. Des., 2018, 154, 360.

49 H. He, W. Cai, Y. Lin and B. Chen, Surface decoration of ZnO nanorod arrays by electrophoresis in the $\mathrm{Au}$ colloidal solution prepared by laser ablation in water, Langmuir, 2010, 26, 8925.

50 P. Wagener, A. Schwenke and S. Barcikowski, How citrate ligands affect nanoparticle adsorption to microparticle supports, Langmuir, 2012, 28, 6132.

51 M. Lau, R. G. Niemann, M. Bartsch, W. O'Neill and S. Barcikowski, Near-field-enhanced, off-resonant laser sintering of semiconductor particles for additive manufacturing of dispersed Au-ZnO-micro/nano hybrid structures, Appl. Phys. A, 2014, 114, 1023.

52 G. Marzun, C. Streich, S. Jendrzej, S. Barcikowski and P. Wagener, Adsorption of colloidal platinum nanoparticles to supports: charge transfer and effects of electrostatic and steric interactions, Langmuir, 2014, 30, 11928.

53 G. K. Podagatlapalli, S. Hamad and S. V. Rao, Trace-level detection of secondary explosives using hybrid silver-gold nanoparticles and nanostructures achieved with femtosecond laser ablation, J. Phys. Chem. C, 2015, 119, 16972.

54 R. A. Ismail and R. S. A. Hamed, Decoration of copper oxide nanoplatelets with gold nanoparticles by laser ablation in methanol for photodetection applications, Opt. Quantum Electron., 2018, 50, 300. 
55 R. Dinkel, J. Jakobi, A. R. Ziefuß, S. Barcikowski, B. Braunschweig and W. Peukert, Role of citrate and $\mathrm{NaBr}$ at the surface of colloidal gold nanoparticles during functionalization, J. Phys. Chem. C, 2018, 122, 27383.

56 H. J. Kim, I. C. Bang and J. Onoe, Characteristic stability of bare Au-water nanofluids fabricated by pulsed laser ablation in liquids, Opt. Lasers Eng., 2009, 47, 532.

57 J. Zhang, M. Chaker and D. Ma, Pulsed laser ablation based synthesis of colloidal metal nanoparticles for catalytic applications, J. Colloid Interface Sci., 2017, 489, 138.

58 M. Gong, D. Y. Wang, C. C. Chen, B.-J. Hwang and H. Dai, A mini review on nickel-based electrocatalysts for alkaline hydrogen evolution reaction, Nano Res., 2016, 9, 28.

59 I. Rogers, M. A. Shipman and M. D. Symes, Earth-abundant catalysts for electrochemical and photoelectrochemical water splitting, Nat. Rev. Chem., 2017, 1, 0003.

60 M.-I. Jamesh and X. Sun, Recent progress on earth abundant electrocatalysts for oxygen evolution reaction (OER) in alkaline medium to achieve efficient water splitting-A review, J. Power Sources, 2018, 400, 31.

$61 \mathrm{C}$. C. $\mathrm{Hu}$ and Y. R. Wu, Bipolar performance of the electroplated iron-nickel deposits for water electrolysis, Chem. Phys., 2003, 82, 588.

62 J. Haenen, W. Visscher and E. Barendrecht, $\mathrm{O}_{2}$ evolution on nickel-cobalt alloys, Electrochim. Acta, 1986, 31, 1541.

63 M. Li, L. Liu, Y. Xiong, X. Liu, A. Nsabimana, X. Bo and L. Guo, Bimetallic $\mathrm{MCo}(\mathrm{M}=\mathrm{Cu}, \mathrm{Fe}, \mathrm{Ni}$, and $\mathrm{Mn})$ nanoparticles doped-carbon nanofibers synthetized by electrospinning for nonenzymatic glucose detection, Sens. Actuators, B, 2015, 207, 614.

64 C. M. Abreu, M. J. Cristóbal, X. R. Nóvoa, G. Pena, M. C. Pérez and R. J. Rodríguez, Modifications of the stainless steels passive film induced by cerium implantation, Surf. Coat. Technol., 2002, 158, 582.

65 P. Si, X. C. Dong, P. Chen and D. H. Kim, A hierarchically structured composite of $\mathrm{Mn}_{3} \mathrm{O}_{4} / 3 \mathrm{D}$ graphene foam for flexible nonenzymatic biosensors, J. Mater. Chem. B, 2013, $1,110$.

66 M. Cabrini, S. Lorenzi and T. Pastore, Cyclic voltammetry evaluation of inhibitors for localised corrosion in alkaline solutions, Electrochim. Acta, 2014, 124, 156.

67 M. Basu, In-situ developed carbon spheres function as promising support for enhanced activity of cobalt oxide in oxygen evolution reaction, J. Colloid Interface Sci., 2018, 530, 264.

68 Y. Zhu, W. Zhou, Z. Chen, Y. Chen, C. Su, M. O. Tadé and Z. Shao, $\mathrm{SrNb}_{0.1} \mathrm{Co}_{0.7} \mathrm{Fe}_{0.2} \mathrm{O}_{3-\delta}$ perovskite as a next-generation electrocatalyst for oxygen evolution in alkaline solution, Angew. Chem., 2015, 127, 3969.

69 X. Xu, C. Su, W. Zhou, Y. Zhu, Y. Chen and Z. Shao, Co-doping Strategy for Developing Perovskite Oxides as Highly Efficient Electrocatalysts for Oxygen Evolution Reaction, Adv. Sci., 2016, 3, 1500187.

70 J. Jiang, A. Zhang, L. Li and L. Ai, Nickel-cobalt layered double hydroxide nanosheets as high-performance electrocatalyst for oxygen evolution reaction, J. Power Sources, 2015, 278, 445.

71 P. He, X.-Y. Yu and X. W. D. Lou, Carbon-incorporated nickel-cobalt mixed metal phosphide nanoboxes with enhanced electrocatalytic activity for oxygen evolution, Angew. Chem., 2017, 129, 3955.

72 K. Lian, S. J. Thorpe and D. W. Kirk, The electrocatalytic activity of amorphous and crystalline Ni-Co alloys on the oxygen evolution reaction, Electrochim. Acta, 1992, 37, 169.

73 F. J. Pérez-Alonso, C. Adán, S. Rojas, M. A. Peña and J. L. G. Fierro, Ni-Co electrodes prepared by electrolessplating deposition. A study of their electrocatalytic activity for the hydrogen and oxygen evolution reactions, Int. J. Hydrog. Energy, 2015, 40, 51.

74 J. A. Creighton and D. G. Eadon, Ultraviolet-visible absorption spectra of the colloidal metallic elements, $J$. Chem. Soc., Faraday Trans., 1991, 87, 3881.

75 D. N. Furlong, A. Launikonis, W. H. Sasse and J. V. Sanders, Colloidal platinum sols. Preparation, characterization and stability towards salt, J. Chem. Soc., Faraday Trans. 1, 1984, 80, 571.

76 J. Zhang, D. N. Oko, S. Garbarino, R. Imbeault, M. Chaker, A. C. Tavares, D. Guay and D. Ma, Preparation of PtAu alloy colloids by laser ablation in solution and their characterization, J. Phys. Chem. C, 2012, 116, 13413.

77 B. M. Hunter, J. D. Blakemore, M. Deimund, H. B. Gray, J. R. Winkler and A. M. Müller, Highly active mixed-metal nanosheet water oxidation catalysts made by pulsed-laser ablation in liquids, J. Am. Chem. Soc., 2014, 136, 13118.

78 T. Löffler, H. Meyer, A. Savan, P. Wilde, A. Garzón-Manjón, Y.-T. Chen, E. Ventosa, C. Scheu, A. Ludwig and W. Schuhmann, Discovery of a multinary noble metal-free oxygen reduction catalyst, Adv. Energy Mater., 2018, 8, 1802269.

79 A. Letzel, S. Reich, T. dos Santos Rolo, A. Kanitz, J. Hoppius, A. Rack, M. P. Olbinado, A. Ostendorf, B. Gökce, A. Plech and S. Barcikowski, Time and Mechanism of Nanoparticle Functionalization by Macromolecular Ligands during Pulsed Laser Ablation in Liquids, Langmuir, 2019, 35, 3038. 